\title{
Regulation of the Invasive Plant Heracleum persicum by Private Landowners in Tromsø, Norway
}

\author{
Sophie Meier, Gregory N. Taff, Jens B. Aune and Sebastian Eiter*
}

In the city of Tromsø in northern Norway, invasive Tromsø palm (Norwegian: Tromsøpalme; English: Persian hogweed) is widespread. Although Tromsø palm has negative impacts on biodiversity and contains a phototoxic sap that burns human skin, it is also considered to be a local symbol of Tromsø city and is appreciated by many inhabitants. This study examined private landowners' characteristics, perceptions, and landowners' regulation of invasive Tromsø palm on their parcels on Tromsø Island in 2012 (vegetation season: May-September) to provide information concerning which landowner groups could be assisted by official regulation. Eleven key informants and 17 landowners were interviewed. Afterward, Tromsø palm on Tromsø Island was mapped using aerial photos and street-level photos from Google Maps ${ }^{\circledR} /$ Google Street View ${ }^{\circledR}$ and fieldwork verification. This distribution map was superimposed on a property map in a geographic information system to produce a map showing private parcels that contained Tromsø palm and associated neighboring parcels that did not contain Tromsø palm. Questionnaires were mailed to the 441 owners of the selected parcels, and 199 of the returned questionnaires were analyzed. Tromsø palm was more likely to be fully regulated/absent on a parcel that was inhabited (particularly if the owner lived on-site) and less likely to be fully regulated/absent if the parcel was jointly managed by several households. These findings indicate that authorities could focus their management efforts on supporting regulation efforts of those private landowners who own currently uninhabited or rented-out parcels and landowners of parcels jointly managed by several households. Furthermore, those landowners who found regulation measures against the plant on Tromsø Island important tended to have partly or fully regulated Tromsø palm on their plots. This might imply that information campaigns from authorities might encourage more landowners to regulate Tromsø palm.

Nomenclature: Tromsø palm (Norwegian: Tromsøpalme; English: Persian hogweed); Heracleum persicum Fischer/ H. laciniatum auct. scand.; non Hornem.

Key words: Hogweed, invasive plants, invasive species management, invasive species mapping, landowner plant regulation behavior.

Globalization has moved the issue of alien and invasive species into the focus of public and scientific attention (McNeely 2001a). "Alien plants" include all plant species that are nonnative to an area and brought there by humans. "Invasive plants" are alien plants that are able to spread over a relatively wide distance within a relatively short time period in the area where they were introduced, e.g., seed plants that

DOI: $10.1017 /$ inp.2017.11

* First and third authors: Forest information systems employee, Forestry Research and Competence Center, Jägerstrasse 1, 99867 Gotha, Germany; second and fourth authors: Research Scientist and Research Scientist, Norwegian Institute for Bioeconomy Research, P.O. Box 115, N-1431 Ås, Norway. Corresponding author's E-mail: meier.so@ t-online.de spread more than $100 \mathrm{~m}$ from the parent plant within less than $50 \mathrm{yr}$ (Richardson et al. 2000). The International Union for Conservation of Nature and Natural Resources additionally defines "invasive species" as species that negatively impact ecosystems and/or human health and that lead to high economic costs (McNeely et al. 2001).

The number of alien plants introduced after $1500 \mathrm{CE}$ (neophytes) has grown with the size of cities in Central Europe (Pyšek 1998). This could be due to the fact that in densely populated areas, seeds of alien plants can be easily spread by displacement of soil and via car tires. Also, alien plant species were planted in gardens from which they could escape and grow in the wild (Hodkinson and Thompson 1997). In the city of Tromsø in northern Norway, an invasive Heracleum species, called "Tromsøpalme" in 


\section{Management Implications}

This study identified private landowners in the city of Tromsø, Norway who do not or only partially regulate invasive Tromsø palm on their parcels, enabling the plant to spread to other parcels. These landowners could be considered primary candidates for education and support by authorities, given limited resources to control the weed. According to the results, private landowners who own currently uninhabited or rented-out parcels would be good candidates to receive financial incentives or other assistance, since the successful management of the plant demands frequent attention and action. Furthermore, the municipality should consider targeting landowners of recently acquired parcels and provide active help and education regarding how to manage the plant in the first years of ownership. Owners of jointly owned parcels were also found to be appropriate candidates to receive plant management assistance. At the same time, the authorities can develop priority areas to focus Tromsø palm control efforts, such as private lands close to public areas, to reduce potential spread onto public lands, and high-population areas, to reduce risk for injuries.

It was shown in the study that some landowners deposit plant waste on their plots instead of using the garbage bin or the municipal waste-disposal site. This can lead to a further spread of the plant on their parcels. Landowners were also found to neglect tending specific areas on their parcels such as border areas or spaces that are hidden or inaccessible, e.g., behind garages or on steep slopes. Authorities might provide assistance or hold information campaigns on regulation of Tromsø palm in neglected areas and proper disposal of plant waste. Officials could improve landowners' control measures at parcel borders by encouraging coordination among landowners and providing education in neighborhood meetings. This study also showed that landowners who perceived Tromsø palm as a problem on Tromsø Island and those who believed in the necessity of regulation measures on Tromsø Island were more likely to have no Tromsø palm or fully controlled Tromsø palm on their property. This may imply that education and information campaigns about the negative effects of invasive species could motivate private landowners to take action.

Norwegian (Heracleum persicum Fischer, Heracleum laciniatum auct. scand., non Hornem.), has spread widely since it was introduced there in the 19th century as an ornamental garden plant (Alm and Jensen 1993; Nilsen 1991). Population genetic analyses showed that Tromsø palm seeds were probably brought from Iran via Great Britain and Finland to northern Norway (Rijal et al. 2015). Jahodová et al. (2007) found that Tromsø palm probably is identical to $H$. persicum. The plant can be found in Iran, Iraq, and Turkey (European and Mediterranean Plant Protection Organization/Organisation Européenne et Méditerranéenne pour la Protection des Plantes [EPPO/OEPP] 2009), and this scientific name is therefore used in this paper.

Tromsø palm (Heracleum persicum) belongs to the family of Apiaceae (Lid and Lid 2005). It has a 1- to 4-cm-wide hollow stem with purple-red spots; the lower part of the stem is often completely purple-red. The plant can grow to 1 - to 4-m high (EPPO/OEPP 2009; Often and Graff 1994). It produces

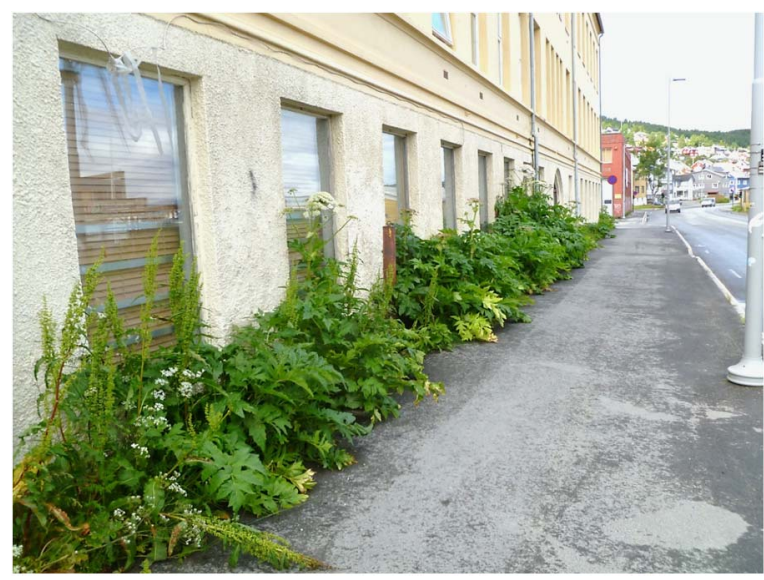

Figure 1. Tromsø palm growing along the wall of a house in Tromsø city, August 2012. (Photo: S. Meier)

white flowers (Lid and Lid 2005) during the summer months (Fröberg 2010). The plant is perennial, reproduces only by seeds, and is polycarpic, which means it can produce seeds several times in its life (EPPO/OEPP 2009; Often and Graff 1994). A single plant produces 6,000 to 8,000 seeds per season (Alm and Often 2006).

The seeds of $H$. persicum can be dispersed by car tires, wind, and water currents. Therefore, the plant is now frequently found in Tromsø along roads and beaches; however, it is also abundant in the city center (Alm et al. 2006; Alm and Often 2006), growing in gardens, neglected green areas, and ditches (see also Figure 1). Inadequate prevention when new roads were built might also have contributed to its spread (key informant: Norwegian Public Road Administration [NPRA, Norwegian: Statens vegvesen] personal communication 2012). For many garden owners in Tromsø, Tromsø palm lost its attractiveness as a garden plant because it was difficult to prevent it from spreading throughout and beyond the garden. Therefore, many garden owners cut down the plants and thoughtlessly threw the plant waste (including mature seeds) on adjacent parcels, thereby contributing to the uncontrolled spread of the plant on Tromsø Island (key informants: Green Warriors of Norway [GWN, Norwegian: Norges Miljøvernforbund] and Tromsø University personal communication 2012).

Since the end of the 1990s, officials and the key informant of GWN have begun to worry about the ecological impacts and the high density of Tromsø palm in Tromsø (key informants: GWN and Troms County governor [Norwegian: Fylkesmannen i Troms] personal communication 2012). Tromsø palm alters cultural landscapes and changes the species composition in the habitats it spreads into (Alm and Jensen 1993). It has been shown on a local scale that Tromsø palm shades out other plants (Myrås and Junttila 1981) and, under laboratory conditions, Tromsø palm seeds constrained 
the growth of neighboring plants by producing suppressive substances (allelopathy) (Junttila 1975). It would be especially problematic if Tromsø palm were to spread beyond urban and human-altered areas into undeveloped natural locations or conservation areas in and around Tromsø (Alm and Jensen 1993). Due to its negative impacts on biodiversity, Tromsø palm has been registered by the Norwegian Biodiversity Information Center (Norwegian: Artsdatabanken) as a high-risk species on the Norwegian blacklist of invasive species (Gederaas et al. 2012).

Aside from Tromsø palm's impact on other plant species, its sap contains furocoumarins (Kavli and Volden 1984) that, in combination with UV radiation (e.g., from the sun), lead to a phototoxic reaction that burns human skin (photodermatitis) (Kavli et al. 1983b). The affected part of the skin can develop blisters (Kavli et al. 1983b) followed by high melanin production (hyperpigmentation) that can last for several months (Kavli et al. 1983a). Children playing outdoors and people working outside, such as gardeners, are especially in danger of exposure to Heracleum sap (Nielsen et al. 2005). Various Heracleum species throughout Europe and North America (e.g., giant hogweed [Heracleum mantegazzianum Sommier \& Levier], Sosnowskyi's hogweed [Heracleum sosnowskyi]) present similar challenges (EPPO/OEPP 2009; Nielsen et al. 2005).

The vigorous growth of the plant and its pervasiveness in Tromsø are probably the reasons why the plant was called a "palm" and named after the city (Alm 2006). Furthermore, for some residents, the plant is a symbol of Tromsø and brings about a sense of local identity (key informants: Tromsø Arts Association [Norwegian: Kunstforeningen Tromsø], Troms County governor, and Tromsø University personal communication 2012). The plant is a popular motif in works of artists, on postcards, for decoration (Alm 2006, 2013), and also for embroidery on a traditional folk costume of Tromsø ("Tromsø festdrakt"), a costume which has been fabricated since ca. 1980. Furthermore, a home for the elderly in Tromsø is called "Heracleum" (Tromsø Municipality [Norwegian: Tromsø kommune] 2015). In the native home range (Iran), part of the plant is used for medication and as food (Hemati et al. 2010), and artists from the Tromsø Arts Association even invited locals to taste soup that included Tromsø palm as an ingredient (Hansen 2014). The problematic aspects of Tromsø palm on the one hand and its local importance as a symbol on the other hand have generated ambivalence toward the plant among locals (key informants: Tromsø Arts Association, GWN, and Tromsø University personal communication 2012); the locals in Tromsø are said to either "love or hate" Tromsø palm (Alm 2013: 42).

The removal of Tromsø palm is time-consuming and demands careful and persistent measures (Nielsen et al. 2005). One way to inhibit the further spread of tall invasive Heracleum, such as Tromsø palm or H. mantegazzianum, is to cut the umbels when they begin to flower to prevent the plant from setting seeds (Nielsen et al. 2005). However, while no such research has been done on $H$. persicum, research with $H$. mantegazzianum showed that, even if umbels are cut before seeds ripen, they are still able to develop viable seeds (Pyšek et al. 2007a), so appropriate disposal of the umbels is important (Pyšek et al. 2007b). To remove invasive Tromsø palm by mowing and cutting of the stems, it is important that the plants are treated at least three times during the growing season (Renna 2002) for not less than $5 \mathrm{yr}$, which exhausts the plant until it finally dies (Nielsen et al. 2005). The plants can also be plowed or the roots can be dug out; the latter usually kills the plant immediately. Cattle and sheep can graze on the area when the plants sprout at the beginning of the growing season. Finally, herbicides are recommended. In all cases, control of the weed can be dangerous due to the risk of coming in contact with the phototoxic sap (see previous discussion of furocoumarins; Nielsen et al. 2005; key informant: Tromsø Municipality personal communication 2012).

Currently, Tromsø palm is widespread in Tromsø and therefore it is a difficult task to regulate this plant (key informants: Tromsø Municipality and Tromsø University personal communication 2012). At the time this study was being conducted, authorities in Tromsø such as the NPRA, the Tromsø County governor, and Tromsø Municipality had planned or had already tried to reduce Tromsø palm in some areas. Due to lack of staff and limited financial resources, the authorities only regulate Tromsø palm sporadically in some specific areas in Tromsø (key informants: GWN, NPRA, Troms County governor, and Tromsø Municipality personal communication 2012). The municipality of Tromsø handles Tromsø palm as part of the normal roadside mowing and as part of the maintenance processes in graveyards and parks (key informant: Tromsø Municipality personal communication 2012). The NPRA tries to inhibit Tromsø palm from spreading beyond Tromsø city by focusing on large roads. NPRA made plans to mow invasive plants along larger roads at a breadth of $3 \mathrm{~m}$ several times during the growing period in future years. Additionally, NPRA wants to obtain permission from landowners to remove invasive plants on private land close to the roads when there is a risk that invasive plants may spread from private parcels to roadsides (key informants: NPRA and Troms County governor personal communication 2012). Overall, official regulation measures in Tromsø have not been conducted on a large scale and are often not done persistently enough to reduce the overall amount of Tromsø palm in the area, with the exception of some specific isolated areas (key informants: NPRA, Troms County governor, and Tromsø Municipality personal communication 2012).

Controlling invasive plants is especially difficult in areas where multiple landowners are involved (Gardener et al. 2010). There are no widely applied official measures to regulate Tromsø palm on private land; Tromsø authorities rely on informing private landowners about health risks and 
methods of regulation. One reason for this might be that there is no jurisdiction for the public authorities to regulate the plant on private land. Furthermore, concern about the plant among most officials is not sufficiently high (key informants: Troms County governor, GWN, and Tromsø Municipality personal communication 2012).

Management plans often do not consider that, e.g., an invasive plant might be perceived as a useful and ornamental garden plant by some locals and might have other positive aspects, such as an emotional meaning or having some economic value; therefore, support for control programs by locals can be low (Blossey 1999; Gardener et al. 2010; Rotherham and Lambert 2011). Management strategies should therefore incorporate public perception of invasive species (Aitken et al. 2009; McNeely 2001b; Qvenild et al. 2014; Rotherham and Lambert 2011; van Wilgen 2012). Daab and Flint (2010) and Fischer and Charnley (2012) found that among private (forest) landowers, those who said they were bothered by invasive plants were significantly more likely to take action against them on their properties. Additionally, Fischer and Charnley (2012) found that owners who have their principal residences on a parcel tend to take significantly more action against invasive plants on that parcel. Research found that values and normative beliefs can play a role in behavioral decisions (e.g., Ajzen and Fishbein 1977; Homer and Kahle 1988), decisions regarding environmentally friendly behavior (e.g., Kollmuss and Agyeman 2002), and supporting decisions regarding wildlife management (Bright and Manfredo 1996; Vaske and Donnelly 1999).

In this study, we investigate how private landowners' regulation behavior is determined by the landowners' sociodemographic and parcel characteristics and the private landowners' evaluation of Tromsø palm's values and of normative beliefs regarding how Tromsø palm should be managed on Tromsø Island. Values describe positive or negative feelings toward something, such as "good or bad" or "ugly or beautiful" (Rokeach 1979:16). For this study, the "aesthetic value" (the appearance of Tromsø palm is evaluated as either ugly or nice) and the "symbolic value" (whether or not Tromsø palm is perceived as an important symbol of Tromsø) are used as defined by Kellert (1996: 14-20). A further value created for this study is the "health value," which addresses whether Tromsø palm is evaluated as being good or dangerous to human health. Normative beliefs in this study refer to whether landowners generally considered Tromsø palm's occurrence on Tromsø Island as problematic and, more specifically, whether regulation of Tromsø palm on Tromsø Island undertaken by local institutions is seen as necessary and to what degree Tromsø palm should be removed. Normative beliefs describe what somebody thinks somebody else is supposed to do or not to do (Fishbein and Ajzen 1975; Zinn et al. 1998).

The specific research issues we address are: How are sociodemographic characteristics, parcel characteristics, values, and normative beliefs related to private landowners' parcels that lead to spread of Tromsø palm, e.g., by not thoroughly regulating Tromsø palm? This study gives insight about the types of private parcels in an urban area that may contribute more to the spread of Tromsø palm than others.

\section{Materials and Methods}

Study Area. The study area is Tromsø Island (Norwegian: Tromsøya, $69.40^{\circ} \mathrm{N}, 18.56^{\circ} \mathrm{E}$ ), which includes the city center of Tromsø, some residential and port areas, and parks (Figure 2). Tromsø Island was chosen as the actual study site because it is a clearly defined area and contains the majority of the city. Tromsø lies in the county of Troms and is the largest town in northern Norway with 67,969 inhabitants (year: 2012); more than half of these inhabitants $(36,088)$ lived on Tromsø Island (Statistics Norway 2016). Tromsø Island is approximately $10-\mathrm{km}$ long and up to $3.6-\mathrm{km}$ wide and ranges in altitude from 0 to $160 \mathrm{~m}$. Tromsø has a humid subarctic climate.

Data Collection. Data were collected between June 2012 and March 2013. At first, semistructured interviews with 11 key informants in Tromsø were conducted. The first key informants were selected from authors of literature about Tromsø palm in Tromsø. Subsequently, key informants were selected by snowball sampling: key informants provided contacts to more key informant interviewees (Marshall 1996). A main criterion for sampling was that the key informants had worked with Tromsø palm in some way. Furthermore, it was important to get a range of different opinions, views, experiences, and factual knowledge concerning the plant. The key informants were asked about different aspects of Tromsø palm (distribution, history, biology, etc.) and how locals perceive and regulate it. Key informants came from authorities in Tromsø (NPRA, Troms County governor, and Tromsø Municipality), an environmental organization (GWN), Tromsø University, and the Tromsø Arts Association. Furthermore, a local Tromsø palm enthusiast was interviewed. In addition, 17 private landowners and 3 renters were interviewed to gather anecdotal information. The interviews were analyzed by identifying topics in the text through "descriptive coding" and "initial coding" (Saldaña 2013: 87-105).

Analysis of the interviews informed the development of a self-administered questionnaire that was subsequently mailed to a sample of private landowners on Tromsø Island. To maximize statistical power, an almost even number of landowners in the sample were gathered who had the plant on their parcels (did not regulate it sufficiently, and thus it was visible in the field in the growing season 2012) and private landowners who did not have the plant on their parcels (or regulated it, so that it was not visible in the field in the 2012 growing season). 


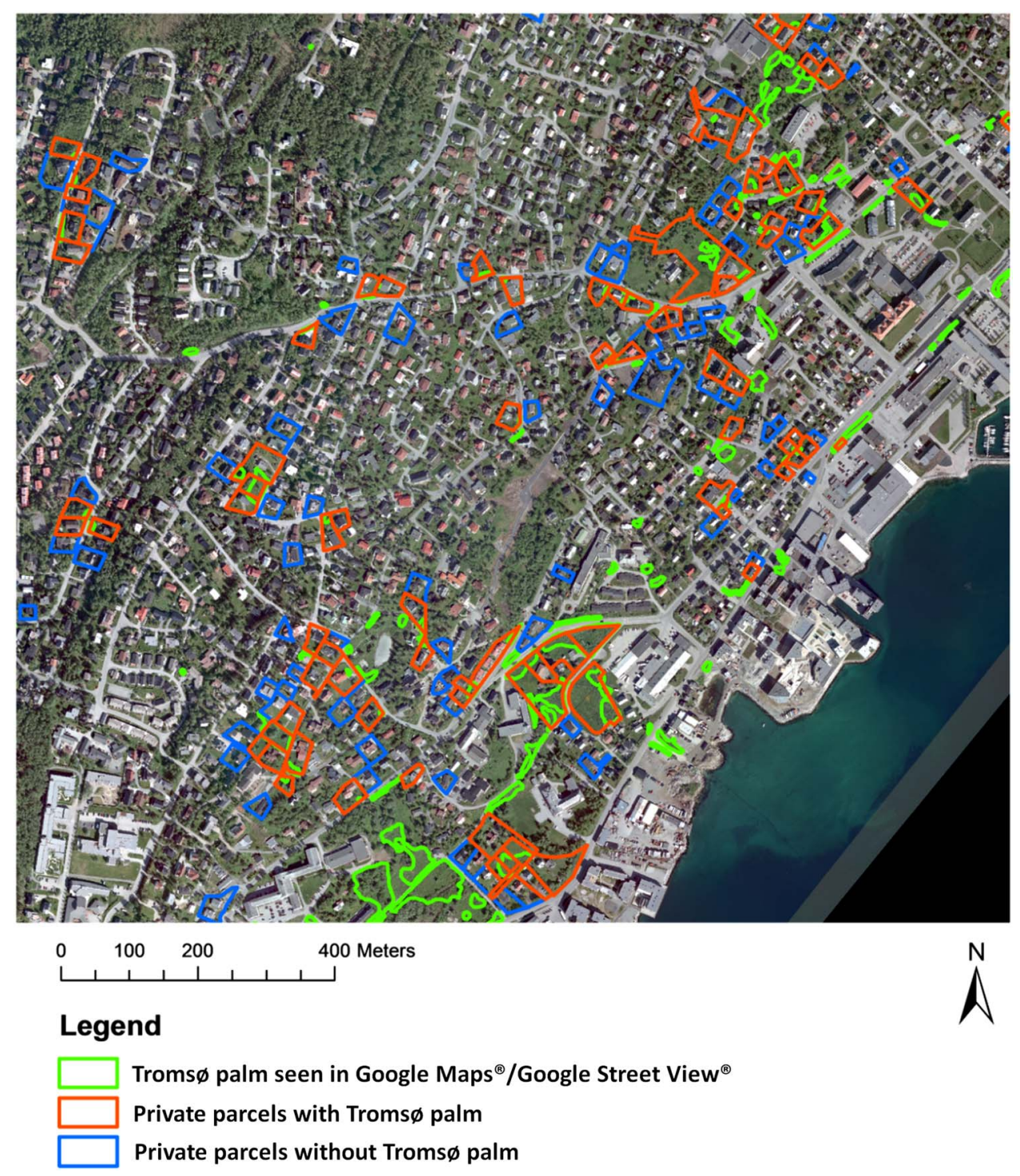

Figure 2. Case-control sampling of private parcels on Tromsø Island, southern area of Tromsø city (Map source: Norwegian Institute of Bioeconomy Research). Status of classification of parcels with Tromsø palm and corresponding parcels without Tromsø palm (chosen in a 20-m radius) based on author's classification by visual interpretation of parcels using Google Maps ${ }^{\circledR}$ and Google Street View ${ }^{\circledR}$. This map was used for field visits to verify the classification of the parcels.

To obtain the sample of landowners, Tromsø palm was mapped on Tromsø Island in ESRI ArcGIS 10. Information about the distribution of Tromsø palm on Tromsø Island was obtained from aerial photos from Google Maps ${ }^{\circledR}$ (year: 2007) and street photos from Google Street View ${ }^{\circledR}$ (year: 2010) (Google Earth 7. 1. 1. 2013; Google Maps 2017). With the help of a cadastral map and an address file (from the Norwegian Mapping Authority), all private parcels on Tromsø Island that contained Tromsø palm were identified and included in the sample (therefore the private parcels with Tromsø palm represent a census on Tromsø Island). For all parcels with Tromsø palm (case), one private neighboring parcel without Tromsø palm (control) within a $20-\mathrm{m}$ radius was randomly selected from the parcel map to achieve a case-control approach. The goal was to have randomly selected control parcels located in the neighborhood of the cases (Schlesselman 1982) (Figure 2). All resulting 441 parcels were surveyed in the field (July to September 2012), and the classification of the parcels (regarding whether or not Tromsø palm was visible on the parcels) was verified and corrected if necessary.

For example, if a non-TP-parcel (parcel without Tromsø palm), classified through Google Maps ${ }^{\circledR} /$ Google Street View ${ }^{\circledR}$, was found in the field to be a TP-parcel (parcel with Tromsø 
palm), its classification was changed to "TP-parcel." Then, two new neighboring non-TP-parcels were selected arbitrarily in the field within $20 \mathrm{~m}$ of the original and newly identified TP-parcel. In the case of a wrongly classified TP-parcel, two new neighboring TP-parcels needed to be chosen.

The questionnaire was developed as a brochure and pretested on landowners during fieldwork. The questionnaire was revised based on feedback from these tests. The questionnaire included sections on the following five topics: (1) parcel characteristics (if the owner vs. only a renter/renters lived on the parcel or if it was uninhabited, the length of ownership, the degree to which vegetation on the parcel was tended, etc.); (2) the presence/absence of Tromsø palm on the respondents' parcel; (3) the degree of regulation of Tromsø palm on the parcel, the handling of the plant material after removal, the responsible person; (4) landowners' evaluations of the aesthetic, health-related, and symbolic value of Tromsø palm (identified as important values from the interviews) and normative beliefs regarding the regulation of Tromsø palm on Tromsø Island; and (5) sociodemographic information about the respondent.

The questionnaire referred to the most recent vegetation period (May-September 2012), also corresponding to the field observations. The respondents were asked to refer to the whole parcel in their answers, even if they only owned parts of a parcel and shared it with other owners. On the cover letter of the survey, a Web link was provided to an online version of the survey, which served as an alternative option for the respondents. Together with a cover letter and a prepaid return envelope, the questionnaires were mailed to all 441 landowners of the sample parcels, with a follow-up reminder by mail after $6 \mathrm{wk}$.

Considering undeliverable addresses (14) and respondents who claimed they were not able to answer (because, for instance, they had never been to the parcel) (3), the effective sample size was 424 . The response rate was $47 \%$ $(n=201)$. Since two respondents indicated that the parcels were partially publicly owned or company owned, 199 questionnaires were included in the analysis. Some classifications of parcels ("with" or "without" Tromsø palm) were revised based on the landowners' answers; for instance, if a parcel appeared to have no Tromsø palm during field checks, but the owner indicated Tromsø palm was present, then that parcel was classified as a parcel with Tromsø palm. However, if the plant had been observed on the parcel during field checks, but the respondent indicated it was not present, the parcel was nevertheless classified as a parcel with Tromsø palm. In the few cases where the presence or absence of the plant on the parcel was unproven based on the field visits, the respondents' answers were considered valid. In cases in which owners did not know whether the plant was on their parcels, the field observations were considered valid. There was only one parcel for which the status of Tromsø palm could not be determined.
During initial fieldwork, we found that landowners with Tromsø palm regulated it to varying degrees. Therefore, landowners were asked in the questionnaire to specify how much they regulated Tromsø palm between May and September 2012: "full regulation, no plant flowered"; "partial regulation, at least one plant flowered (which means the plant could still spread)"; "no regulation, the plant could grow and spread unhindered on the parcel." The regulation behavior was also categorized according to the parcels' contribution to the potential spread of Tromsø palm (full regulation or Tromsø palm absent vs. no or partial regulation). The term "regulation" includes all sorts of measures that can be taken to prevent the spread of Tromsø palm, such as cutting of stems, cutting of flowers, digging out roots, mowing, or using an herbicide.

Statistical Analyses. Univariate, bivariate, and multivariate analyses were conducted by using IBM SPSS Statistics v. 20 . Logistic regressions were used to determine which independent variables (sociodemographic variables, parcel characteristics, landowner values and normative beliefs) were associated most strongly with the outcome variables regarding Tromsø palm regulation. We conducted both binary and multinomial logistic regressions to account for the two different ways to categorize outcomes of Tromsø palm regulation on the parcels (cf. Field 2009; Singh 2007). The binary method considered two possible outcomes: parcels from where Tromsø palm (1) has or (2) does not have the potential to spread to other parcels, which included the whole dataset including parcels with no Tromsø palm as not having the potential to spread. The multinomial method only considered parcels where the owners were aware of Tromsø palm's presence on their parcel, with three possible outcomes: Tromsø palm was (1) not, (2) partially, or (3) fully regulated.

For each regression type, two models were run, so four regression models were developed: a binary logistic regression model (model I) and a multinomial logistic regression model (model II), each including the independent variable "frequency of tending the vegetation-covered area on parcel"; and another binary (model III) and multinomial regression model (model IV), each including instead the independent variable "residence status: owners lived on the parcels vs. only renters lived on the parcels vs. no residence on the parcels." Two models of both the regression types were developed, because the variables "frequency of tending the vegetation-covered area on the parcels" and "residence status" could not be included in a single model, as the other variables in the model became non-significant, likely due to a small sample size. The models with the independent variable "frequency of tending the vegetation-covered area" (models I and II) showed the highest number of significant results and therefore are primarily discussed in this paper. In all four regression models, outliers were removed according to Field (2009). 


\section{Results and Discussion}

Respondents' and Parcels' Characteristics. Tables 1 (continuous and ordinal variables), 2, and 3 (categorical variables) summarize the sociodemographic variables of the questionnaire respondents, the characteristics of their parcels, and their evaluations of Tromsø palm's values and of their normative beliefs regarding Tromsø palm's regulation on Tromsø Island. As many respondents did not answer all questions, the total number of observations was different for each variable (max. 199, see "Data Collection"). Regarding parcel characteristics, almost all respondents were owners of their parcels; only one respondent was a renter (Table 2). Therefore, "landowner" is used as a synonym for "respondent" in the following sections.

\section{Predictors for Tromsø Palm's Status on Landowners'} Parcels. This section presents and discusses how sociodemographic characteristics, parcel characteristics, values, and normative beliefs were associated with Tromsø palm's potential to spread as seen with the binary logistic regression analysis. Furthermore, it is shown how the variables were associated with the regulation degree of Tromsø palm on the landowners' parcels (no, partial, or full regulation) in multinomial logistic regression analyses. As outlined in the "Materials and Methods," four models were developed, but models I and II, which showed the highest number of significant results, are mainly discussed here. When variables were significant in both the binary (model I) and multinomial logistic regression (model II), only the results of the binary logistic regression are presented. The results of the multinomial model are discussed only if variables proved to be significant exclusively in the multinomial logistic regression. Furthermore, bivariate analyses were conducted regarding regulation behavior and the different variables. Only those significant results of the bivariate statistics that were either not significant in the regressions or showed a different direction are presented in this paper. In some cases of bivariate statistics, the sample sizes were too small to apply Chi-square tests.

The Nagelkerke pseudo- $\mathrm{R}^{2}$ values in the binary logistic regression models were 0.194 for the binary model I $(n=176)$ and 0.145 for the binary model III $(n=178)$, while the values were 0.365 for the multinomial model II

Table 1. Studied variables (part 1): respondents' (landowners') sociodemographic characteristics, parcel characteristics, values, and normative beliefs.

\begin{tabular}{|c|c|c|c|c|c|c|}
\hline Variable & Min & Max & Mean & Median & SD & $\begin{array}{c}n \\
\text { (total) }\end{array}$ \\
\hline \multicolumn{7}{|l|}{ Sociodemographic characteristics } \\
\hline Age (years) & 20 & 93 & 57.16 & 59 & 14.715 & 194 \\
\hline Household income in $2011^{\mathrm{a}}$ & 1 & 5 & 3.64 & 4.0 & 1.179 & 146 \\
\hline Number of persons living in respondent's household & 1 & 14 & 2.69 & 2.0 & 1.519 & 194 \\
\hline Years respondent lived in Tromsø (residence time) & $<1$ & 85 & 40.91 & 40 & 19.317 & 196 \\
\hline \multicolumn{7}{|l|}{ Parcel characteristics } \\
\hline Years of parcel ownership & 1 & 96 & 21.58 & 18.0 & 16.003 & 192 \\
\hline $\begin{array}{l}\text { Frequency of tending the vegetation-covered area on parcels between } \\
\text { May and September } 2012^{\mathrm{b}}\end{array}$ & 1 & 6 & 3.97 & 4.0 & 1.463 & 192 \\
\hline \multicolumn{7}{|l|}{ Evaluation of values ${ }^{c}$} \\
\hline Aesthetic value & 1 & 5 & 3.19 & 3.0 & 1.351 & 195 \\
\hline Health value & 2 & 5 & 3.62 & 3.0 & 0.766 & 195 \\
\hline Symbolic value & 1 & 5 & 2.8 & 3 & 1.415 & 194 \\
\hline \multicolumn{7}{|l|}{ Evaluation of normative beliefs ${ }^{\mathrm{d}}$} \\
\hline Occurrence of Tromsø palm on Tromsø Island & 1 & 5 & 3.66 & 4.0 & 1.170 & 195 \\
\hline Necessity of control measures against Tromsø palm on Tromsø Island & 1 & 5 & 4.25 & 5.0 & 1.020 & 194 \\
\hline
\end{tabular}

${ }^{a}$ Attributes of income: 1: less than 300,000 Norwegian kroner (NOK); 2: 300,000-450,000 NOK; 3: 450,000-600,000 NOK; 4: 600,000-1,000,000 NOK; 5: more than 1,000,000 NOK.

${ }^{\mathrm{b}}$ Attributes of frequency of tending the vegetation (e.g., cutting hedges, mowing, weeding): 1: never; 2: less than once per year; 3: once per month; 4: several times per month; 5: once per week; 6: several times per week.

${ }^{\mathrm{c}}$ Attributes of evaluation of values: Aesthetic value (appearance of Tromsø palm), 1: ugly to 5: nice. Health value (health impact of Tromsø palm) 1: positive impact to 5: negative impact. Symbolic value (symbolic importance of TP for Tromsø), 1: not important to 5: important.

${ }^{\mathrm{d}}$ Attributes of evaluation of normative beliefs: occurrence of Tromsø palm on Tromsø Island: 1: do not perceive Tromsø palm as a problem on Tromsø Island to 5: perceive Tromsø palm as a problem on Tromsø Island. Necessity of regulation measures (done by institutions) against Tromsø palm on Tromsø Island, 1: not necessary to 5: necessary.

172 • Invasive Plant Science and Management 10, April-June 2017 
Table 2. Studied variables (part 2): respondents' (landowners') sociodemographic characteristics and parcel characteristics.

\begin{tabular}{|c|c|c|c|c|}
\hline Variable & & Proportion (\%) & $n$ & $\begin{array}{c}n \\
\text { (total) }\end{array}$ \\
\hline & Sociodemographic characteristics & & & \\
\hline Education & $\begin{array}{l}\text { With higher education (fulfilled university degree or } \\
\text { polytechnical high school)/without higher education }\end{array}$ & $69.4 / 30.6$ & $134 / 59$ & 193 \\
\hline Permanent injuries & Parcel characteristics & & & \\
\hline Respondent status & Respondent was owner/renter & $99.5 / 0.5$ & $198 / 1$ & 199 \\
\hline Residence status & $\begin{array}{l}\text { Owners (in some cases along with renters) lived on parcel/ } \\
\text { only renters lived on parcel/no residence on parcel }\end{array}$ & $83.8 / 9.9 / 6.3$ & $160 / 19 / 12$ & 191 \\
\hline $\begin{array}{l}\text { Degree Tromsø palm should be } \\
\text { removed (by local authorities) } \\
\text { from Tromsø Island }\end{array}$ & $\begin{array}{l}\text { Normative belief } \\
\text { Full removal (eradication)/partial removal (from some } \\
\text { areas)/no removal anywhere }\end{array}$ & $33.0 / 64.3 / 2.7$ & $60 / 117 / 5$ & 182 \\
\hline
\end{tabular}

$(n=120)$ and 0.260 for the multinomial model IV $(n=120)$. These values are not too low, considering that these variables measure human behavior. The $\mathrm{R}^{2}$ values are somewhat higher in the multinomial models II and IV, which means the variables in these models fit the regression better compared with the binary models I and III. However, this might not be related to the fact that the variables in the multinomial models explain the outcome better compared with the binary models, but rather that the data set used for the multinomial models is different (a subset of the data used for the binary models).
To summarize, parcels from which Tromsø palm does not have the potential to spread (having no or fully regulated Tromsø palm) compared with parcels where Tromsø palm has the potential to spread (not or partly regulated) tend to have the following characteristics (based on the binary logistic regression, model I [Table 4] and model III): a more frequently tended vegetation-covered area (only model I); owners who live on the parcel compared with only renters or no residents (only model III); only one household is responsible for the parcel compared with several; more people live in the respondent's household (only model I);

Table 3. Studied variables (part 3): the outcome variables of the regression analyses.

\begin{tabular}{|c|c|c|c|c|}
\hline Variable & & Proportion (\%) & $n$ & $\begin{array}{c}n \\
\text { (total) }\end{array}$ \\
\hline & Regulation behavior & & & \\
\hline $\begin{array}{l}\text { Degree Tromsø palm was regulated between } \\
\text { May and September } 2012^{\mathrm{b}}\end{array}$ & $\begin{array}{l}\text { Parcel with full regulation/partial } \\
\text { regulation/no regulation }\end{array}$ & $44.3 / 35.7 / 20.0$ & $62 / 50 / 28$ & 140 \\
\hline
\end{tabular}

${ }^{a}$ This is the outcome variable of the binary logistic regression. For one parcel, the status of Tromsø palm on the parcel was not known; therefore, the binary regression included 198 parcels instead of 199.

b This is the outcome variable of the multinomial logistic regression. These analyses included only parcels from those landowners who knew that they had Tromsø palm on their parcels between May and September 2012. Full regulation: no plant flowered on the parcel; partial regulation: at least one plant flowered on the parcel; no regulation: there were no measures against Tromsø palm in that period. 
Table 4. Significant variables affecting probability of potential of Tromsø palm (TP) to spread on Tromsø Island (left column) and TP being regulated partially (at least one plant flowered on the parcels) or fully (no plant flowered on the parcels) (middle and right columns).

\begin{tabular}{|c|c|c|c|c|c|c|c|c|c|c|c|c|}
\hline \multirow[b]{3}{*}{ Independent variables ${ }^{\mathrm{b}}$} & \multirow{2}{*}{\multicolumn{4}{|c|}{$\begin{array}{c}\begin{array}{c}\text { Outcome variable of binary logistic } \\
\text { regression }(\text { model I) }\end{array} \\
\text { TP was fully regulated or absent on } \\
\text { respondent's parcel }\end{array}$}} & \multicolumn{8}{|c|}{ Outcome variables of multinomial logistic regression (model II) ${ }^{\mathrm{d}}$} \\
\hline & & & & & \multicolumn{4}{|c|}{$\begin{array}{l}\text { TP was partially regulated on } \\
\text { respondent's parcel }\end{array}$} & \multicolumn{4}{|c|}{$\begin{array}{l}\text { TP was fully regulated on } \\
\text { respondent's parcel }\end{array}$} \\
\hline & B & SE & P-value & Odds & B & SE & P-value & Odds & B & SE & P-value & Odds \\
\hline Constant (model I)/intercept (model II) & -4.461 & 0.908 & 0.000 & 0.012 & -8.761 & 2.250 & 0.000 & - & -9.258 & 2.271 & 0.000 & - \\
\hline $\begin{array}{l}\text { Frequency parcel's vegetation was tended } \\
\quad(1: \text { never; 6: several times per week from May to September 2012) }\end{array}$ & 0.348 & 0.119 & 0.003 & $1.416^{* * *}$ & 0.917 & 0.265 & 0.001 & $2.501^{* * *}$ & 1.058 & 0.264 & $<0.001$ & $2.881^{* * *}$ \\
\hline Residence status (reference: only renter(s) on parcel) & & & 0.025 & & & & & & & & & \\
\hline Owner(s) lived on parcel & 1.138 & 0.652 & 0.081 & $3.121^{*}$ & -1.441 & 1.211 & 0.234 & 0.237 & -0.639 & 1.232 & 0.604 & 0.528 \\
\hline No residence on parcel & -0.435 & 0.944 & 0.645 & 0.647 & -3.584 & 1.664 & 0.031 & $0.028^{* *}$ & -3.356 & 1.694 & 0.048 & $0.035^{* *}$ \\
\hline $\begin{array}{l}\text { No. of households associated with parcel: } \\
\text { Several households (reference: one household) }\end{array}$ & - & - & - & - & 1.623 & 0.697 & 0.020 & $5.068^{* *}$ & 0.702 & 0.686 & 0.307 & 2.017 \\
\hline One household (reference: several households) & 0.831 & 0.357 & 0.020 & $2.294^{* *}$ & - & - & - & - & - & - & - & - \\
\hline Length of parcel ownership & - & - & - & - & 0.057 & 0.026 & 0.029 & $1.059^{* *}$ & 0.037 & 0.026 & 0.147 & 1.038 \\
\hline No. of persons living in respondent's household & 0.378 & 0.138 & 0.006 & $1.460^{* * *}$ & - & - & - & - & - & - & - & - \\
\hline $\begin{array}{l}\text { Evaluating TP's occurrence on Tromsø Island } \\
\text { (1: not perceived as problem; } 5 \text { : perceived as problem) }\end{array}$ & 0.486 & 0.151 & 0.001 & $1.626^{* * *}$ & - & - & - & - & - & - & - & - \\
\hline $\begin{array}{l}\text { Evaluating the necessity of regulating TP on Tromsø Island } \\
\text { (1: not necessary; } 5 \text { : necessary) }\end{array}$ & - & - & - & - & 1.028 & 0.332 & 0.002 & $2.796^{* * *}$ & 1.262 & 0.340 & $<0.001$ & $3.531^{* * *}$ \\
\hline
\end{tabular}

${ }^{\mathrm{a}}$ Both models refer to the period between May and September 2012.

${ }^{\mathrm{b}}$ Bivariate analysis showed that on parcels where TP was partially regulated, there was a higher percentage belonging to the category of not being inhabited by children below the age of 10 compared with parcels inhabited by children. However, the inclusion of the variable "children ( $<10 \mathrm{yr})$ lived/did not live on the parcel with residence" made other variables non-significant in the multinomial logistic regressions; therefore, it was left out. The variable "residence status" was run in separate binary (model III) and multinomial (model IV) logistic regression models including all the variables except "Frequency the vegetation-covered area on the parcels was tended."

${ }^{c}$ Nagelkerke pseudo- $\mathrm{R}^{2}=0.194$ (maximum: 1.0), $n=176$, reference category: "Troms $\varnothing$ palm was partly regulated/not regulated on the parcels"; no outlier removed.

${ }^{\mathrm{d}}$ Nagelkerke pseudo- $\mathrm{R}^{2}=0.365$ (maximum 1.0), $n=120$, reference category: "no regulation of Troms $\varnothing$ palm on parcels"; two outliers removed.

${ }^{* * *}$ Significant at $0.01 ;{ }^{* *}$ significant at $0.05 ;^{*}$ significant at 0.1 . 
and the respondent holds the normative belief that Tromsø palm's occurrence is a problem on Tromsø Island.

Considering only those landowners who had (and were aware of) Tromsø palm on their parcels, full and/or partial regulation of Tromsø palm, compared with no regulation, was associated with those parcels (based on the multinomial logistic regression, model II [Table 4] and model IV) that had only renters compared with being uninhabited (only model IV), were owned for a longer time, and the respondent holds the normative belief that regulation measures against Tromsø palm are necessary on Tromsø Island. In contrast to the binary logistic regression result, the multinomial regression model II showed that parcels shared between several households (as compared with those with just one household) had a higher probability of having Tromsø palm partly regulated compared with it not being regulated. Using the same data set of landowners who had (and were aware of) Tromsø palm on their parcels, bivariate analysis (Chi-square test) showed that residential parcels without children (younger than $10 \mathrm{yr}$ ) more often had partly regulated Tromsø palm compared with residential parcels with children, which more often had unregulated Tromsø palm.

The significant result that a higher frequency of regulating the vegetation-covered areas is associated with having no Tromsø palm or fully regulated Tromsø palm can also be supported by field observations. They showed that parcels with mown lawns and cut hedges generally had less Tromsø palm.

The almost significant finding that no Tromsø palm or fully regulated Tromsø palm is more commonly found on parcels inhabited by their owners, as compared with those inhabited by renters (binary model III, reference level: "only renter(s) lived on parcel"), was also encountered in interviews with a landowner and a renter: one owner in the questionnaire gave as a reason why Tromsø palm was not tended that the renter was responsible for the vegetation on the parcel but was not doing anything. In another case, it was found in an interview that a renter saw the responsibility as lying with her landlord, who did not feel responsible. Although the finding is only near significant $(\mathrm{P}=0.081)$, it could represent an effect, because the sample size generally was small.

Furthermore, differences in parcels with and without any resident(s) were investigated. Compared with uninhabited parcels, plots where the owners lived tended to have significantly more fully regulated or absent Tromsø palm (a version of binary model III with "no residence on parcel" as the reference level, $\mathrm{P}=0.029$, odds $=4.823$ ). Additionally, running the multinomial model IV (reference level: "only renter(s) lived on parcel"), parcels where only renters lived had significantly more partly ${ }^{1}(\mathrm{P}=0.031$, odds $=35.714)$ or fully ${ }^{2}(\mathrm{P}=0.048$, odds $=28.571)$ regulated Tromsø

\footnotetext{
${ }^{1}$ As parcels where only renters lived was the reference level, the inverse of the odds for the parcels without residence (Table 4) corresponded to the odds of the parcels with only renters: $35.714=1 / 0.028$.

${ }^{2} 28.571=1 / 0.035$ (Table 4$)$.
}

palm, compared with uninhabited parcels. Having a resident on the parcel was significantly associated with tending the vegetation-covered area more frequently in bivariate analysis (Kruskal-Wallis test: $\mathrm{P}<0.001, n=190$ ).

During field visits, it could be seen that on parcels without residents (no buildings or empty buildings for sale), Tromsø palm often spread unchecked. Much Tromsø palm was found in an undeveloped area at the shore. In an interview, the owner of this plot said she did not tend the vegetation there because she planned to sell the parcel to the municipality, and she did not know that Tromsø palm was on the plot. Similarly, Fischer and Charnley (2012) found that forest landowners who are living on their parcels have a higher probability of regulating invasive plants on their properties, and the authors assumed that living on the parcels makes it easier for the landowners to tend their properties and to regulate the growth of invasive plants.

The binary regression (model I and III) showed that parcels associated with just one household significantly more often tended to have plots that were fully regulated or had no Tromsø palm, compared with jointly owned plots. However, the multinomial regression (model II) showed that jointly owned parcels significantly tended to have a higher percentage of partially regulated than nonregulated Tromsø palm, as compared with singlehousehold plots.

Having jointly owned parcels could be an advantage for at least partially regulating Tromsø palm, as there are more people who can do some garden work, and there is often community work on shared parcels (this is a Norwegian custom called a dugnad), which had been indicated by one questionnaire respondent from a jointly owned parcel. However, one-household parcels seem to obtain better results in regulating Tromsø palm so thoroughly that it does not spread. Probably, on jointly owned parcels, there is a lack of one person/family feeling the complete obligation toward managing the parcel, because the more people are present in a problematic situation, the less each individual often feels responsible to solve the problem (Bell et al. 2001). Furthermore, on jointly owned parcels, landowners might not know which part they are responsible for and therefore regulate Tromsø palm only partially. Additionally, jointly owned parcels could be larger than single-household parcels and may be less easy to manage. In this context, the effect of the parcel size on the regulation of Tromsø palm could be examined in a further study, although Fischer and Charnley (2012) found no impact of parcel size on the regulation behavior of forest landowners.

The longer a parcel is owned, the significantly higher is the probability that the plant is regulated partly or even fully (multinomial models II and IV); a possible explanation could be that it takes several years of consistent regulation measures to remove $H$. persicum (Nielsen et al. 2005). 
Also, respondents who have owned land for a longer time might be more interested in taking care of the land.

Bivariate analysis showed that a significantly higher percentage of residential parcels where children (younger than $10 \mathrm{yr}$ ) lived were not regulated for Tromsø palm: $33.3 \%$ of child-inhabited parcels $(n=8)$ vs. $13.9 \%$ for no-child parcels $(n=14)$; whereas a higher percentage of (residential) parcels where no children lived were partly regulated: $41.6 \%$ for parcels with no children $(n=42)$ vs. $20.8 \%$ of parcels with children $(n=5)$ (there was no difference regarding full regulation) (Chi-square test: $\mathrm{P}=0.041, n=125)$. This result was unexpected, as it was assumed that parents might be more vigilant in controlling Tromsø palm to protect their children from the phototoxic sap. The inclusion of the variable "children's presence or absence on the parcels" into the regression models led to the non-significance of other included variables, and therefore this variable was omitted.

More persons living in a household was associated with having fully regulated or no Tromsø palm on the parcel (binary model I). A reason might be that larger households offer more workforce to take care of Tromsø palm. Other sociodemographic variables (such as age, gender, income, time period of being resident in Tromsø, education) or having incurred injuries due to Tromsø palm were not found to be significantly related to the potential of the Tromsø palm to spread or to the degree of Tromsø palm regulation.

Respondents who hold the normative belief that Tromsø palm's occurrence on Tromsø Island is a problem were significantly associated with owning parcels where Tromsø palm is fully regulated or absent (binary model I and III). The multinomial regression models II and IV showed that those who regulated the plant at least partly or fully were significantly associated with holding the normative belief that regulation measures for Tromsø palm on Tromsø Island are necessary. This is comparable to the findings of Daab and Flint (2010) and Fischer and Charnley (2012) that being worried about invasive species is related to landowners regulating invasive plants on their own properties.

There was no significant association in how landowners indicated their normative beliefs toward the degree Tromsø palm should be removed from Tromsø Island by institutions and the landowners' regulation behaviors on their parcels (however, for the Chi-square tests, the number of respondents favoring no removal was below five, so they were excluded from this test, and it was therefore not possible to make a statement about these respondents). These results might show that Tromsø palm is evaluated differently depending on whether the question refers to the plant that grows on the landowners' parcels or to Tromsø palm in general. This phenomenon was also found during an interview with a landowner who mentioned that she had removed the plant completely from her parcel, but at the same time she appreciated it along the roads and the shore. This duality of some locals' evaluation was mentioned by all key informants, e.g., from Tromsø University: "People have mixed feelings [...]. Sometimes they like it and think it is a bit impressive in a way because it is so large and they like to take pictures of it in the winter when the dry stems are decorative and so forth. But they do not want to have [the plant] in their own garden."

Contrary to some of the normative beliefs, none of the values investigated in this study (aesthetic, health-related, and symbolic) were significant in any of the four regression models. The normative beliefs are more directly associated with the topic "regulation of Tromsø palm" and therefore might have more influence on the regulation behaviors of landowners than general values of the plant (cf. Ajzen and Fishbein 1977).

Additional Findings Regarding Tromsø Palm's Spread and Regulation. Regarding the question "How was the plant material of Tromsø palm handled after it was removed? (mark all answers that apply)," most respondents (the question was answered by those who either partially or fully regulated Tromsø palm on their parcels) indicated that the plant waste was disposed on the parcel, either in a compost heap $\left(43.8 \%, n=49, n_{\text {total }}=112\right)$ and/or on the ground $(32.1 \%, n=36)$. Fewer respondents indicated that the plant waste was taken away from the parcel and deposited in the garbage/organic waste container $(24.1 \%$, $n=27)$ and/or the municipal waste disposal site $(10.7 \%$, $n=12$ ). Leaving the plant waste on the parcel must be regarded as unfavorable, as it can contribute to the continued spread of the plant, which has been shown in the case of giant hogweed (Pyšek et al. 2007a).

To answer the question "How did/does Tromsø palm end up on your parcel? (mark all answers that apply)," $37.9 \%\left(n=53, n_{\text {total }}=140\right)$ of all respondents who had Tromsø palm on their parcels indicated that it spread from neighboring parcels, while $26.4 \%$ assumed it spread from roadsides $(n=37)$. This shows that a number of respondents felt they had to deal with a constant intrusion of plants from adjacent areas. Field observations revealed that if Tromsø palm existed on a parcel, it could often be found on neighboring parcels as well. During fieldwork, it was observed that Tromsø palm was often growing along parcel borders-possibly because the responsibilities for these areas were not clear-and Tromsø palm was often found in inaccessible or steep areas on parcels. The results of the other answer options for the question regarding how Tromsø palm ended up on the parcel are beyond the scope of this paper and therefore not presented here.

\section{Implications for Tromsø Palm Management on Private} Parcels. Many landowners may leave their parcels for vacation for several weeks during the summer months, so there are generally fewer people available to tend the private land at the time when Tromsø palm flowers and seeds. 
Because of this and the factors mentioned in the previous section, help from public authorities seems necessary for control. According to the results of this study, private landowners who will most likely need support from authorities if resources were available might be, for instance, those who own parcels without residents. These parcels can present problems, as the successful management of the plant demands active and consistent control. The owners of these parcels could receive financial incentives or active help from authorities. Furthermore, the municipality could benefit by targeting landowners who recently bought their parcels and help them through education and assistance in controlling the plant during the first years of ownership. In addition, owners of parcels that are jointly owned are appropriate candidates to receive active or financial help, because they were found to have problems regulating the plant fully or removing it. Authorities could also try to get permission from landowners to regulate the plant on private land close to public areas to prevent the plant from spreading onto public land. Additionally, densely populated areas could be the focus of regulation measures to minimize health risks.

The finding that landowners who consider the plant as problematic on Tromsø Island also regulated the plant more could imply that education and information campaigns about the negative effects of invasive species could motivate private landowners to take action. In addition, landowners could be better informed about disposal of cut plant parts in garbage bins or at the municipal waste disposal site to prevent further spread, based on findings about giant hogweed seed ripening by Pyšek et al. (2007a). Authorities should also inform landowners about taking particular care of border areas and hidden or inaccessible spaces in their information campaigns and assistance programs. These programs could be delivered through leaflets and neighborhood meetings where neighbors would have the opportunity to coordinate the regulation.

Key informants from Tromsø University and GWN did not believe that the Tromsø palm could be eradicated from Tromsø Island, and the key informant from Tromsø University was concerned that measures would require a lot of resources. Gardener et al. (2010) investigated the success of eradication efforts against invasive plants in the Galapagos. Based on their results, it might be difficult to regulate the plant on private areas on Tromsø Island because many landowners are involved. There will always be landowners who do not voluntarily regulate Tromsø palm rigorously enough, and there might be areas on a parcel where the plant is more difficult to regulate. Therefore, the plant will always find places where it can grow and from which it can spread. Furthermore, Gardener et al. (2010) found that if invasive plants are too widespread and well established, eradication might no longer be possible. In such situations, Rotherham and Lambert (2011) believe that management of invasive species needs to be more pragmatic, not aiming at eradicating the species but controlling it, as invasive species management is an open-ended process. In this way, the study might give some hints as to which private areas the authorities could target.

Potential Bias in the Study. Selecting key informants by snowball sampling is considered the most appropriate method if the total study population is not known (Faugier and Sargeant 1997), and some participants might have more knowledge than others (Marshall 1996). However, according to Griffiths et al. (1993), this selection method might lead to a sample that is biased toward the worldview of those key informants who provided the most contacts for further informants, because potential informants not known by the key informants had a lower likelihood of being included in the study. To minimize this bias, care was taken to continue to find and interview key informants until a wide range of opinions, worldviews, and people from different professions were included in the sample.

In 92 of 199 answered questionnaires, there were missing answers. Seven respondents even seemed to have overlooked whole pages of the questionnaire due to the brochure format. Moreover, there was a small sample size for parcels without a residence (12 of 191 respondents who answered this question), and it was therefore difficult to get clear results about differences between parcels with and without residents.

\section{Acknowledgements}

We thank the many landowners and renters in Tromsø who contributed to the study. We would also like to thank the key informants from Tromsø Municipality (Tromsø Kommune), Troms County governor (Fylkesmannen i Troms), Norwegian National Road Administration in Tromsø (Statens vegvesen), University of Tromsø, and the Tromsø Arts Association (Kunstforeningen Tromsø), and the other residents who agreed to be interviewed. Thanks also to Harald Hals Karlsen for translating the questionnaire into Norwegian. Special thanks we owe to the anonymous reviewers for their valuable comments on earlier versions of the manuscript. The German Academic Exchange Service, the Department of International Environment and Development Studies at Norwegian University of Life Sciences, and the Norwegian Institute of Bioeconomy Research provided financial support for the project (RCN grant nos. 194052 and 194051).

\section{Literature Cited}

Aitken M, Rangan H, Kull CA (2009) Living with alien invasives. The political ecology of wattle in the eastern highveld Mpumalanga South Africa. Études Océan indien 42-43:115-141 
Ajzen I, Fishbein M (1977) Attitude-behavior relations: a theoretical analysis and review of empirical research. Psychol Bull 84:888-918

Alm T (2006) Tromsø palm i folketradisjonen [Tromsø palm and traditions]. Ottar 261:18-24. Norwegian

Alm T (2013) Ethnobotany of Heracleum persicum Desf. ex Fisch., an invasive species in Norway, or how plant names, uses, and other traditions evolve. J Ethnobiol Ethnomed 9:42

Alm T, Jensen C (1993) Tromsøpalmen (Heracleum laciniatum auct. scand.) - noen kommentarer til artens innkomst og ekspansjon i NordNorge [Heracleum laciniatum auct. scand.-notes on its introduction and expansion in northern Norway]. Blyttia 51:61-69

Alm T, Jensen C, Often A (2006) Tromsøpalmens historie [History of Tromsø palm]. Ottar 261:3-9. Norwegian

Alm T, Often A (2006) Tromsøpalmen og dens slektninger-et knippe pestplanter [Tromsø palm and its relatives-a collection of pest plants]. Ottar 261:10-17. Norwegian

Bell PA, Greene TC, Fisher JD, Baum A (2001) Environmental Psychology. Fort Worth, TX: Harcourt College Publishers. $634 \mathrm{p}$

Blossey B (1999) Before, during and after: the need for long-term monitoring in invasive plant species management. Biol Invasions 1:301-311

Bright AD, Manfredo MJ (1996) A conceptual model of attitudes toward natural resource issues: a case study of wolf reintroduction. Hum Dimens Wildl 1:1-21

Daab MT, Flint CG (2010) Public reaction to invasive plant species in a disturbed Colorado landscape. Invasive Plant Sci Manag 3:390-401

[EPPO/OEPP] European and Mediterranean Plant Protection Organization/Organisation Européenne et Méditerranéenne pour la Protection des Plantes (2009) Heracleum mantegazzianum, Heracleum sosnowskyi and Heracleum persicum. European and Mediterranean Plant Protection Organization (EPPO) data sheet on invasive alien plants. Bull OEPP 39:489-499

Faugier J, Sargeant M (1997) Sampling hard to reach populations. J Adv Nurs 26:790-797

Field A (2009) Discovering statistics using SPSS. London: Sage. $821 \mathrm{p}$

Fischer AP, Charnley S (2012) Private forest owners and invasive plants: risk perception and management. Invasive Plant Sci Manag 5:375-389

Fishbein M, Ajzen I (1975) Belief, attitude, intention, and behavior: an introduction to theory and research. Reading, MA: AddisonWesley. $578 \mathrm{p}$

Fröberg L (2010) Heracleum L. Pages 224-234 in Jonsell B \& Karlsson T, eds. Flora Nordica Volume 6, Thymelaeaceae to Apiaceae. Stockholm: Swedish Museum of Natural History

Gardener MR, Atkinson R, Rentería JL (2010) Eradications and people: Lessons from the plant eradication program in Galapagos. Restor Ecol 18:20-29

Gederaas L, Moen TL, Skjelseth S, Larsen LK (2012) Fremmede arter i Norge-med norsk svarteliste 2012 [Invasive species in Norwaywith the Norwegian blacklist 2012]. Trondheim: Artsdatabanken. 212 p. Norwegian

Google Earth 7.1.1. (2013) Tromsø Island, 6940'06.75"N, $18^{\circ}$ 56'18.01'E. elevation 0-160m. Google

Google Maps (2017) Tromsø Island, 6940'06.75"N, 1856'18.01"E. http://maps.google.com/. Accessed: April 29, 2017

Griffiths P, Gossop M, Powis B, Strang J (1993) Reaching hidden populations of drug users by privileged access interviewers: methodological and practical issues. Addiction 88:1617-1626
Hansen S (2014) Lager suppe av Tromsøpalmen [Preparing soup of Tromsø palm] iTromsø. http://www.itromso.no/nyheter/ article9810579.ece, accessed April 29, 2017

Haugen BSH (2006) Norsk bunadleksikon: Alle norske bunader og samiske folkedrakter [Encyclopedia of Norwegian Local Costumes: All Norwegian and Sami Local Costumes]. Oslo: Damm. 399 p. Norwegian

Hemati A, Azarnia M, Angaji SA (2010) Medicinal effects of Heracleum persicum (Golpar). Middle East J Sci Res 5:174-176

Hodkinson DJ, Thompson K (1997) Plant dispersal: the role of man. J Appl Ecol 34:1484-1496

Homer PM, Kahle LR (1988) A structural equation test of the value-attitude-behavior hierarchy. J Pers Soc Psychol 54: 638-646

Jahodová S, Trybush S, Pyšek P, Wade M, Karp A (2007) Invasive species of Heracleum in Europe: An insight into genetic relationships and invasion history. Divers Distrib 13:99-114

Junttila O (1975) Allelopathy in Heracleum laciniatum: inhibition of lettuce seed germination and root growth. Physiol Plant 33:22-27

Kavli G, Volden G (1984) Phytophotodermatitis. Photodermatology 1:65-75

Kavli G, Volden G, Midelfart K, Haugsbø S, Prytz JO (1983a) Phototoxicity of Heracleum laciniatum. Case reports and experimental studies. Contact Dermatitis 9:27-32

Kavli G, Volden G, Midelfart K, Krokan H, Prytz JO, Haugsbø S (1983b) In vivo and in vitro phototoxicity of different parts of Heracleum laciniatum. Contact Dermatitis 9:269-273

Kellert SR (1996) The Value of Life: Biological Diversity and Human Society. Washington, DC: Island Press. 263 p

Kollmuss A, Agyeman J (2002) Mind the gap: why do people act environmentally and what are the barriers to pro-environmental behavior? Environ Educ Res 8:239-260

Lid J, Lid DT (2005) Norsk flora [Norwegian Flora]. Oslo: Samlaget. 1230 p. Norwegian

Marshall MN (1996) Sampling for qualitative research. Fam Pract 13:522-525

McNeely JA (2001a) Preface. Pages 1-2 in McNeely JA, ed. The Great Reshuffling: Human Dimensions of Invasive Alien Species. Gland, Switzerland/Cambridge, UK: IUCN

McNeely JA (2001b) An introduction into human dimensions of invasive alien species. Pages 5-20 in McNeely JA, ed. The Great Reshuffling: Human Dimensions of Invasive Alien Species. Gland, Switzerland/ Cambridge, UK: IUCN

McNeely JA, Mooney HA, Neville LE, Schei PJ, Waage JK (2001) Global Strategy on Invasive Alien Species. Gland, Switzerland/ Cambridge, UK: IUCN, Global Invasive Species Programme. $63 \mathrm{p}$

Myrås $\mathrm{H}$, Junttila $\mathrm{O}$ (1981) Interaction between Heracleum laciniatum and some other plants. Holarctic Ecol 4:43-48

Nielsen C, Ravn HP, Nentwig W, Wade M, eds (2005) The Giant Hogweed Best Practice Manual: Guidelines for the Management and Control of an Invasive Weed in Europe. Hørsholm, Denmark: Forest \& Landscape Denmark. $44 \mathrm{p}$

Nilsen EW (1991) Tromsøpalmen [The Tromsø palm]. Polarflokken 15:149-150. Norwegian

Often A, Graff G (1994) Skillekarakterer for kjempebjørnekjeksHeracleum mantegazzianum-og tromsøpalme- $H$. 'laciniatum' [Characteristics separating Heracleum mantegazzianum and H. laciniatum]. Blyttia 52:129-133. Norwegian

178 - Invasive Plant Science and Management 10, April-June 2017 
Pyšek P (1998) Alien and native species in Central European urban floras: a quantitative comparison. J Biogeogr 25:155-163

Pyšek P, Krinke L, Jarošik V, Perglová I, Pergl J, Moravcová L (2007a) Timing and extent of tissue removal affect reproduction characteristics of an invasive species Heracleum mantegazzianum. Biol Invasions 9:335-351

Pyšek P, Perglová I, Krinke L, Jarošik V, Pergl J, Moravcová L (2007b) Regeneration ability of Heracleum mantegazzianum and implications for control. Pages 112-125 in Pyšek P, Cock MJW, Nentwig W \& Ravn HP, eds. Ecology and Management of Giant Hogweed (Heracleum mantegazzianum). Wallingford, UK: CABI

Qvenild M, Setten G, Skår M (2014) Politicising plants. Invasive alien species and domestic gardening. Nor J Geogr 27:10-12

Renna R (2002) Bekjemping av tromsøpalme —en håpløs oppgave? [Fighting Tromsø palm—a hopeless task?]. Polarflokken 26:101-102. Norwegian

Richardson DM, Pyšek P, Rejmánek M, Barbour MG, Panetta FD, West CJ (2000) Naturalization and invasion of alien plants: concepts and definitions. Divers Distrib 6:93-107

Rijal DP, Alm T, Jahodová S, Stenøien HK, Alsos IG (2015) Reconstructing the invasion history of Heracleum persicum (Apiaceae) into Europe. Mol Ecol 24:5522-5543

Rokeach M (1979) Understanding human values: individual and societal. New York: Free Press. $322 \mathrm{p}$

Rotherham ID, Lambert RA (2011) Good science, good history and pragmatism: managing the way ahead. Pages 355-365 in Rotherham ID \& Lambert RA, eds. Invasive and Introduced Plants and Animals. Human Perceptions, Attitudes and Approaches to Management. London: Earthscan

Saldaña J (2013) The Coding Manual for Qualitative Researchers. London: Sage. 303 p
Schlesselman JJ (1982) Case-Control Studies: Design, Conduct, Analysis. New York: Oxford University Press. 359 p

Singh K (2007) Quantitative Social Research Methods. New Delhi: Sage. $432 \mathrm{p}$

Statistics Norway (2016) Population, by Basic Statistical Unit. http://www. statistics.no/statistikkbanken/SelectVarVal/Define.asp?MainTable= FolkGrunnkrKom\&KortNavnWeb=folkemengde $\&$ PLanguage $=1 \&$ checked=true. Accessed: April 29, 2017

Tromsø Municipality (2015) Heracleum Nursing Home. http://www. tromso.kommune.no/heracleum.121288.no.html. Accessed: April 29, 2017

van Wilgen BW (2012) Evidence, perceptions, and trade-offs associated with invasive alien plant control in the Table Mountain National Park, South Africa. Ecol Soc 17:23

Vaske JJ, Donnelly MP (1999) A value-attitude-behavior model predicting wildland preservation voting intentions. Soc Natur Resour 12:523-537

Zajdela F, Bisagni E (1981) 5-Methoxypsoralen, the melanogenic additive in sun-tan preparations, is tumorigenic in mice exposed to $365 \mathrm{~nm}$ u.v. radiation. Carcinogenesis 2:121-127

Zinn HC, Manfredo MJ, Vaske JJ, Wittmann K (1998) Using normative beliefs to determine the acceptability of wildlife management actions. Soc Nat Resour 11:649-662

Received January 22, 2016, and approved January 31, 2017.

Associate Editor for this paper: John A. Randall, University of California, Davis. 